
\title{
3 Research Square \\ Randomized Longitudinal Study Comparing 3 Nasal Respiratory Support Modes to Prevent Intermittent Hypoxia in Very Preterm Infants
}

\section{Maximilian Gross}

Universitatsklinikum Tubingen Klinik fur Kinder- und Jugendmedizin https://orcid.org/0000-0002-48130563

\section{Anette Poets}

Universitatsklinikum Tubingen Klinik fur Kinder- und Jugendmedizin

\section{Renate Steinfeldt}

Vivantes Klinikum Neukolln

\section{Michael S. Urschitz}

Johannes-Gutenberg Universitat Mainz Institut fur Medizinische Biometrie Epidemiologie und Informatik

\section{Katrin Böckmann}

Universitatsklinikum Tubingen Klinik fur Kinder- und Jugendmedizin

\section{Bianca Haase}

Universitatsklinikum Tubingen Klinik fur Kinder- und Jugendmedizin

Christian F. Poets ( $\nabla$ christian-f.poets@med.uni-tuebingen.de )

https://orcid.org/0000-0002-1072-0066

\section{Research article}

Keywords: Very low birthweight infant, nasal respiratory support, s-NIPPV, NCPAP, intermittent hypoxia

Posted Date: July 6th, 2020

DOI: https://doi.org/10.21203/rs.3.rs-39735/v1

License: (c) (1) This work is licensed under a Creative Commons Attribution 4.0 International License. Read Full License 


\section{Abstract}

Background: Nasal continuous positive airway pressure (NCPAP) devices using variable (vf-) and continuous (cf-) flow or synchronized nasal intermittent positive pressure ventilation (s-NIPPV) are used to prevent or treat intermittent hypoxia $(\mathrm{IH})$ in preterm infants. Results on which is most effective vary. We aimed to investigate the effect of s-NIPPV and vf-NCPAP compared to cf-NCPAP on the rate of IH episodes.

Methods: Preterm infants with a gestational age of 24.9-29.7 weeks presenting with IH while being treated with cf-NCPAP were monitored for 8 hours, then randomized to $8 \mathrm{~h}$ of treatment with vf-NCPAP or s-NIPPV. Data from 16 infants were analyzed. Due to an unexpectedly low sample size, results are only reported descriptively.

Results: No relevant changes in the rate of IH events were detected between cf- vs. vf-NCPAP or between cf-NCPAP vs. s-NIPPV.

Conclusion: Although limited by its small sample size, s-NIPPV, vf- and cf-NCPAP seemed to be similarly effective in the treatment of $\mathrm{IH}$ in these infants.

Trial registration: This study was registered with the German Clinical Trials register - DRKS00005387. Registered 12 November 2013, https://www.drks.de/drks_web/navigate.do? navigationld=trial.HTML\&TRIAL_ID=DRKS00005387

\section{Background}

Nasal continuous positive airway pressure (NCPAP) is effective for treating apnea of prematurity (AOP) and preventing intermittent hypoxia $(\mathrm{IH})[1]$. It helps keeping the airways open [2] and improves oxygenation [3] as well as lung function [4]. NCPAP may also reduce work of breathing, at least if applied via devices with variable gas flow (variable flow = vf-NCPAP) $[5,6]$. Besides NCPAP, nasal intermittent positive pressure ventilation (NIPPV) is used to treat AOP or IH. In meta-analysis, the latter was found to be more effective than NCPAP in preventing re-intubation, but only if synchronized with the infant's own breathing efforts (s-NIPPV) [7-9].

In an earlier study, we compared continuous flow (cf-) with vf-NCPAP and NIPPV concerning the rate of hypoxemic episodes and observed less such episodes with vf-NCPAP. NIPPV in that study, however, was not synchronized to the infants' own breathing efforts [10].

In the present study, we aimed to investigate the effect of s-NIPPV on the rate of IH episodes comparing cf-NCPAP with vf-NCPAP and s-NIPPV.

\section{Methods}




\section{Patients}

Between October 2014 and September 2019, infants admitted to the neonatal intensive care unit at Tübingen University Children's Hospital were evaluated for their eligibility to participate in this study. Inclusion criteria were (i) gestational age (GA) at birth $\leq 34 \mathrm{wk}$, (ii) postmenstrual age at study $\leq 38 \mathrm{wk}$, (iii) persistent $A O P$, and (iv) frequent apneas, expressed as an apnea score $\geq 5$ on a rating scale used in the unit [11], despite treatment with caffeine and cf-NCPAP. The apnea score assigned points depending on the response of the nursing staff to events involving bradycardia (heart rate $<80 /$ minute) or hypoxemia $\left(\mathrm{SpO}_{2}<80 \%\right)$. If no intervention was needed one point was given; two points if tactile stimulation was given or a manual inspiration via the ventilator, and 3 points if the baby had to be turned over in preparation for bagging; eight points were given if the baby was felt to briefly need positive pressure ventilation to recover. The respective points were added up. Exclusion criteria were severe congenital malformations, neuromuscular conditions or chromosomal abnormalities, the presence of symptomatic apnea (e.g., due to sepsis, hypoglycemia or cerebral hemorrhage), or lack of written informed parental consent.

\section{Study design}

The study design included two different before-after studies involving one control and two test interventions (Fig. 1). After having entered the study, infants continued on their standard NCPAP device (control intervention) for $8 \mathrm{~h}$ or until they had reached a value of $\geq 10$ on the above apnea score, at which time they were randomized, using sequentially numbered opaque concealed envelopes prepared by an assistant not involved in patient care, to either vf-NCPAP (test intervention 1, Infant Flow Plus (Vyaire Medical Inc., Chicago, IL) or s-NIPPV via a standard neonatal ventilator (test intervention 2, Sophie, Fritz Stephan, Gackenbach, Germany). Starting with this initial $8 \mathrm{~h}$ run-in phase, infants had their heart rate and arterial oxygen saturation (measured by pulse oximetry; $\mathrm{SpO}_{2}$ ) recorded on a standard infant monitor (Vitaguard VG 3100, GeTeMed, Teltow, Germany) in $3 \mathrm{sec}$ averaging mode; these recordings continued without delay after infants had been switched to their respective study ventilator. Otherwise, infants received their routine care, including treatment with caffeine base $(5 \mathrm{mg} / \mathrm{kg} / \mathrm{day})$.

\section{Recordings of physiological signals}

The above monitor stored pulse rate and $\mathrm{SpO}_{2}$, as well as pulse waveforms, perfusion index and signal IQ continuously. These recordings were analyzed using proprietary software (VitaWin ${ }^{\circledR}$, GeTeMed) after completing study recruitment, thus not influencing any clinical decisions. Recordings were evaluated manually and periods with artifactual signal, defined as a signal IQ $<0.2$, excluded [12]. IH was defined as a decrease in $\mathrm{SpO}_{2}$ to $<80 \%$ for $>1 \mathrm{sec}$, bradycardia as a fall in heart rate to $<80$ beats per minute for more than one beat. The fraction of inspired oxygen $\left(\mathrm{FiO}_{2}\right)$ and transcutaneous partial pressure of carbon dioxide $\left(\mathrm{tcpCO}_{2}\right)$ were recorded via the unit's patient data management system (PDMS; IntelliSpace, 
Philips, Eindhoven, NL) that also included electronic documentation of the above apnea score as entered by the nursing staff. Average $\mathrm{FiO}_{2}$ and $\mathrm{tcpCO}_{2}$ were calculated as the mean of the values documented every 30 minutes by the PDMS.

\section{Ventilators}

While a standard neonatal ventilator (Sophie) was used to generate cf-NCPAP or s-NIPPV; vf-NCPAP was delivered using the Infant Flow Plus. The NCPAP level was set to $5 \mathrm{cmH}_{2} \mathrm{O}$ throughout. S-NIPPV was delivered at a rate of 20 breaths/minute and a peak pressure of $15 \mathrm{cmH}_{2} \mathrm{O}$. Synchronization with the infants' breathing efforts was achieved by an abdominal pneumatic trigger capsule (Respiration Sensor, Fritz Stephan). Respiratory support was delivered via binasal prongs of appropriate size (EasyFlow, Fritz Stephan, or Infant Flow LP, Vyaire Medical Inc., Chicago, IL).

\section{Statistical analysis}

Primary endpoint was the rate of $\mathrm{IH}$ events per hour. Secondary endpoints were the rate of bradycardia events per hour, mean $\mathrm{FiO}_{2}$ and mean $\mathrm{tcpCO}_{2}$. Based on our previous study [10], we estimated that 26 patients per before-after study were required to detect a paired group difference of $30 \%$, i.e. a reduction by $0,85 \mathrm{IH}$ events/hour. However, patient recruitment took much longer than expected, so that the study ultimately had to be terminated after 27 infants had been recruited over 5 years (see below). Thus, results were reported descriptively stratified by before-after study (median, minimum, maximum) and treatment effects were estimated based on the mean of the individual differences (paired samples) and its corresponding $95 \%$ confidence interval $(95 \% \mathrm{Cl})$. No statistical hypothesis testing and no comparisons between vf-NCPAP and s-NIPPV were performed on this smaller-than-expected sample size.

\section{Results}

Patient flow is shown in Fig. 2, and patient demographics in Table 1. Regarding our primary endpoint, no clinically relevant changes in the rate of IH events were detected between cf- vs. vf-NCPAP or between cfNCPAP vs. s-NIPPV (Table 2). The treatment effects $(95 \% \mathrm{Cl})$ were estimated to be 0.25 events per hour $(-0.23$ to $0.73 ; n=10)$ for vf-NCPAP and -0.33 events per hour $(-1.07$ to $0.40 ; n=6)$ for s-NIPPV. 
Table 1

Patient demographics, expressed as median (minimum-maximum)

\begin{tabular}{|llll|}
\hline & Total group $(\mathrm{n}=16)$ & vf-NCPAP $(\mathrm{n}=10)$ & s-NIPPV $(\mathrm{n}=\mathbf{6})$ \\
\hline Male sex $(\mathrm{n})$ & 4 & 3 & 1 \\
\hline GA at birth $(\mathrm{wk})$ & $27.5(24.9-29.7)$ & $27(24.9-29.7)$ & $28.4(27-29)$ \\
\hline Birth weight $(\mathrm{g})$ & $755(590-1050)$ & $718(590-987)$ & $940(620-1050)$ \\
\hline PMA at study $(\mathrm{wk})$ & $30.5(27.3-31.9)$ & $30.2(27.3-31.9)$ & $30.5(29.4-31.1)$ \\
\hline
\end{tabular}

Table 2

Primary and secondary endpoints expressed as median (minimum-maximum)

\begin{tabular}{|lllll|}
\hline & $\begin{array}{l}\text { Before-After Study } 1 \\
(\mathbf{n = 1 0})\end{array}$ & $\begin{array}{l}\text { Before-After Study } 2 \\
(\mathbf{n = 6})\end{array}$ & s-NIPPV \\
\hline & vf-NCPAP & cf-NCPAP & $0.69(0-1.6)$ \\
\hline $\mathrm{IH}$ rate $(\mathrm{n} / \mathrm{h})$ & $1.38(0-2.5)$ & $1.06(0.13-2.9)$ & $0.88(0-2.1)$ & $0.44(0.1-0.5)$ \\
\hline Bradycardias $(\mathrm{n} / \mathrm{h})$ & $0.56(0-1.3)$ & $0.25(0-1.1)$ & $0.81(0.5-0.9)$ & $0.21(0.21-$ \\
\hline Mean $\mathrm{FiO}_{2}$ & $0.23(0.21-$ & $0.22(0.21-$ & $0.21(0.21-$ & $0.25)$ \\
\hline $\begin{array}{l}\text { Mean tcpCO } \\
(\mathrm{mmHg})\end{array}$ & $0.28)$ & $0.29)$ & $61.3(48-64)$ & $54.3(50-64)$ \\
\hline
\end{tabular}

Comparing both CPAP-modes, tcpCO $\mathrm{CO}_{2}$ was $3-4 \mathrm{mmHg}$ lower during vf-NCPAP or s-NIPPV support compared to cf-NCPAP, while $\mathrm{FiO}_{2}$ remained unchanged (Table 2).

\section{Discussion}

In this comparison of the effectiveness of vf-NCPAP and s-NIPPV in reducing IH rates in very preterm infants with AOP compared to standard treatment with cf-NCPAP, we found only little difference between these 3 nasal respiratory support systems.

We had planned this study for a total recruitment of 52 infants. This proved impossible for several reasons: There were competing large interventional multicenter studies ongoing on the unit with recruitment taking place in the first 1-2 postnatal days, reducing the number of infants eligible for the present study. Also, many infants who had initially reached an apnea score of $\geq 5$ subsequently did not reach the score of 10 required for randomization to another nasal respiratory support system, so that they never qualified for randomization. The slow patient recruitment in part was also due to a lack of external funding, so that no dedicated research personnel was available to supervise the study. Thus, after extending the original recruitment period by more than 2 years, the study eventually was terminated 
prematurely, because recruitment would have lasted another 8 years had it continued at the pace seen. This decision prohibited applying any statistical testing; nonetheless, results showed only minor differences at a descriptive level, suggesting that either intervention had similar effectiveness.

Further limitations include the fact that we did not record apneas. However, in line with previous work from our group, we do not see this as a relevant limitation, as it is not the apnea, but its consequences, i.e. $\mathrm{IH}$ and, to a lesser extent, bradycardia, that are relevant to the long-term outcome of preterm infants [13].

Perhaps due to these limitations, differences seen between the various nasal ventilator support systems were smaller than in other studies. For example, Gizzi et al., using a pneumotachograph-based system to synchronize the ventilator with the babies' breathing efforts and focusing on both bradycardia and IH, found a $50 \%$ reduction in the rate of IH episodes during s-NIPPV compared to cf-NCPAP (median, 2.9 vs. $5.9 / \mathrm{h}$, respectively) [9]. In our earlier study, comparing vf- with cf-NCPAP, differences in bradycardia-/IHrates were also larger ( 2.8 vs. $5.4 / \mathrm{h}$ [10]). Thus, although gestational age at birth and postmenstrual age at study were similar in all three studies, cardiorespiratory event rates were lower in the present study, but s-NIPPV again seemed to be more effective than vf-NCPAP. As averaging times on the pulse oximeters used were identical, we have no explanation for the lower overall event rates other than this being a chance finding related to our small sample size.

A different approach to nasal respiratory support for preterm infants has recently been introduced by the nasal application of the neurally adjusted ventilatory assist (NAVA) technique in preterm infants. Using this technique in 8 preterm infants studied at a median post-menstrual age of $29 \mathrm{wk}$, a $40 \%$ reduction in

the number of episodes with $\mathrm{SpO}_{2}<80 \%$ was found; episodes were also of significantly shorter duration while infants received NAVA [14]. This may thus be a valuable addition to treating AOP via nasal respiratory support systems, but yet needs further study.

Thus, although our data showed a smaller decrease in the rate of IH events than seen previously, they are in line with these previous studies in that we also found less IH and fewer bradycardias during s-NIPPV compared to cf-NCPAP.

\section{Conclusion}

Given the above limitations of our study, particularly its small sample size, the comparatively small differences seen between the three different modes of nasal respiratory support investigated should not prevent clinicians from preferring s-NIPPV or vf-NCPAP over cf-NCPAP when trying to prevent or treat IH episodes in very preterm infants.

\section{List Of Abbreviations}

AOP apnea of prematurity

cf continuous flow 
$\mathrm{FiO}_{2}$ fraction of inspired oxygen

GA gestational age

IH intermittent hypoxia

NAVA neurally adjusted ventilatory assist

NCPAP nasal continuous positive airway pressure

PDMS patient data management system

s-NIPPV synchronized nasal intermittent positive pressure ventilation

$\mathrm{SpO}_{2}$ peripheral oxygen saturation

tcpCO $\mathrm{C}_{2}$ transcutaneous partial pressure of carbon dioxide

vf variable flow

wk week

\section{Declarations}

\section{Ethics approval and consent to participate}

The study was approved by the ethics committee of the medical faculty of Tübingen University (No. 433/2014B01). Written parental consent was obtained upon patient recruitment.

\section{Consent for publication}

Not applicable.

\section{Availability of data and materials}

The datasets used and/or analyzed during the current study are available from the corresponding author on reasonable request.

\section{Competing interests}

The authors have no conflicts of interest to declare. 


\section{Funding}

No external funding was secured for this study, but we acknowledge support by the Open Access Publishing Fund of Tübingen University

\section{Authors' contributions}

MG took part in patient recruitment, analyzed the monitor recordings, performed statistical analysis and wrote the first draft of the manuscript. AP developed the study design and initiated the study. RS developed the study design and took part in patient recruitment. MU took part in developing the study design and contributed to the statistical analysis. KB took part in patient recruitment and the statistical analysis. $\mathrm{BH}$ took part in patient recruitment and supervised the study during the extension of the recruiting period. CP initiated and supervised the study and revised the manuscript for important intellectual input. All authors approved the final manuscript as submitted and agree to be accountable for all aspects of the work.

\section{Acknowledgement}

The authors thank Magnus von Lukowicz for helping with patient recruitment.

\section{Statement}

This study adheres to CONSORT guidelines. A completed CONSORT checklist on information necessary to report a randomized trial was attached to the manuscript.

\section{References}

1. Eichenwald EC, Committee on Fetus, Newborn, American Academy of Pediatrics. Apnea of Prematurity. Pediatrics. 2016;137(1).

2. Miller MJ, Carlo WA, Martin RJ. Continuous positive airway pressure selectively reduces obstructive apnea in preterm infants. J Pediatr. 1985;106(1):91-4.

3. Krouskop RW, Brown EG, Sweet AY. The early use of continuous positive airway pressure in the treatment of idiopathic respiratory distress syndrome. J Pediatr. 1975;87(2):263-7.

4. Richardson CP, Jung AL. Effects of continuous positive airway pressure on pulmonary function and blood gases of infants with respiratory distress syndrome. Pediatr Res. 1978;12(7):771-4.

5. Klausner JF, Lee AY, Hutchison AA. Decreased imposed work with a new nasal continuous positive airway pressure device. Pediatr Pulmonol. 1996;22(3):188-94. 
6. Pandit PB, Courtney SE, Pyon KH, Saslow JG, Habib RH. Work of breathing during constant- and variable-flow nasal continuous positive airway pressure in preterm neonates. Pediatrics. 2001;108(3):682-5.

7. Lemyre B, Davis PG, De Paoli AG, Kirpalani H. Nasal intermittent positive pressure ventilation (NIPPV) versus nasal continuous positive airway pressure (NCPAP) for preterm neonates after extubation. Cochrane Database Syst Rev. 2017;2:CD003212.

8. Tang S, Zhao J, Shen J, Hu Z, Shi Y. Nasal intermittent positive pressure ventilation versus nasal continuous positive airway pressure in neonates: a systematic review and meta-analysis. Indian Pediatr. 2013;50(4):371-6.

9. Gizzi C, Montecchia F, Panetta V, Castellano C, Mariani C, Campelli M, et al. Is synchronised NIPPV more effective than NIPPV and NCPAP in treating apnoea of prematurity (AOP)? A randomised crossover trial. Arch Dis Child Fetal Neonatal Ed. 2015;100(1):F17-23.

10. Pantalitschka T, Sievers J, Urschitz MS, Herberts T, Reher C, Poets CF. Randomised crossover trial of four nasal respiratory support systems for apnoea of prematurity in very low birthweight infants. Arch Dis Child Fetal Neonatal Ed. 2009;94(4):F245-8.

11. Poets CF. Interventions for apnoea of prematurity: a personal view. Acta Paediatr. 2010;99(2):172-7.

12. Urschitz MS, Von Einem V, Seyfang A, Poets CF. Use of Pulse Oximetry in Automated Oxygen Delivery to Ventilated Infants. Anesth Analg. 2002;94:S37-S40.

13. Poets CF. Intermittent hypoxia and long-term neurological outcome: How are they related? Semin Fetal Neonatal Med. 2019:101072.

14. Gibu CK, Cheng PY, Ward RJ, Castro B, Heldt GP. Feasibility and physiological effects of noninvasive neurally adjusted ventilatory assist in preterm infants. Pediatr Res. 2017;82(4):650-7.

\section{Figures}



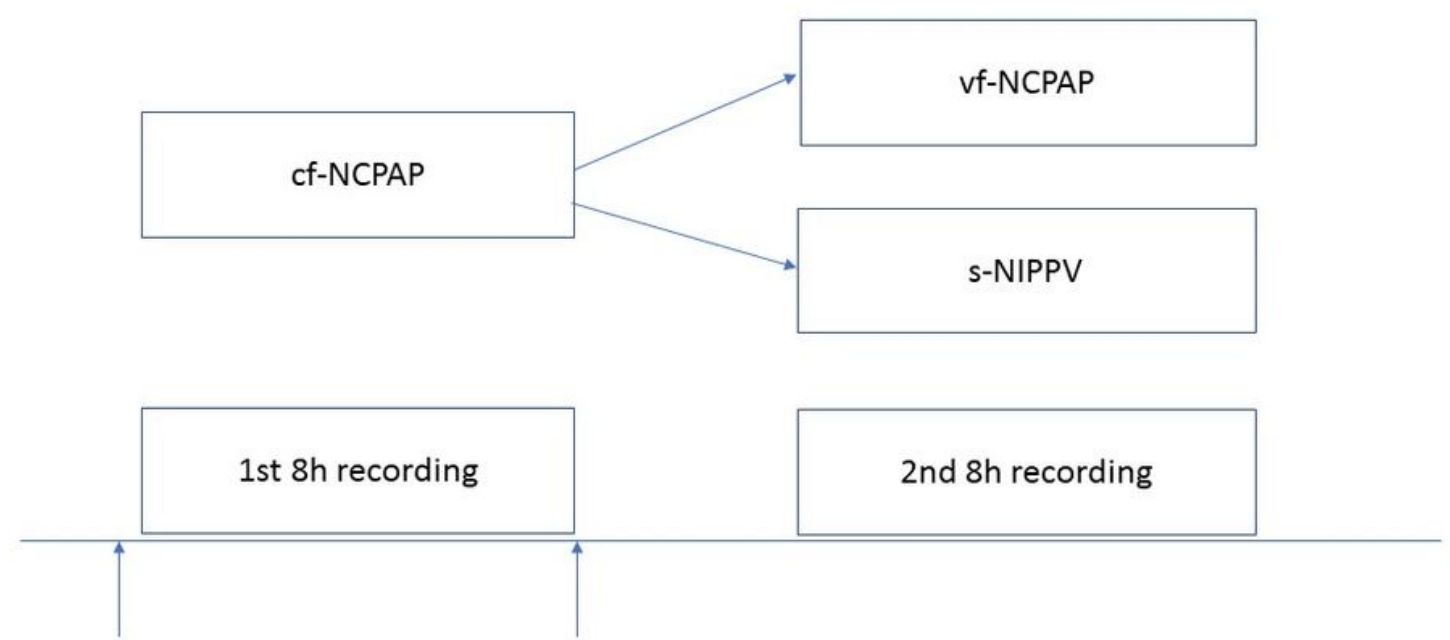

Parental consent

Randomigiven

\section{Figure 1}

Study design

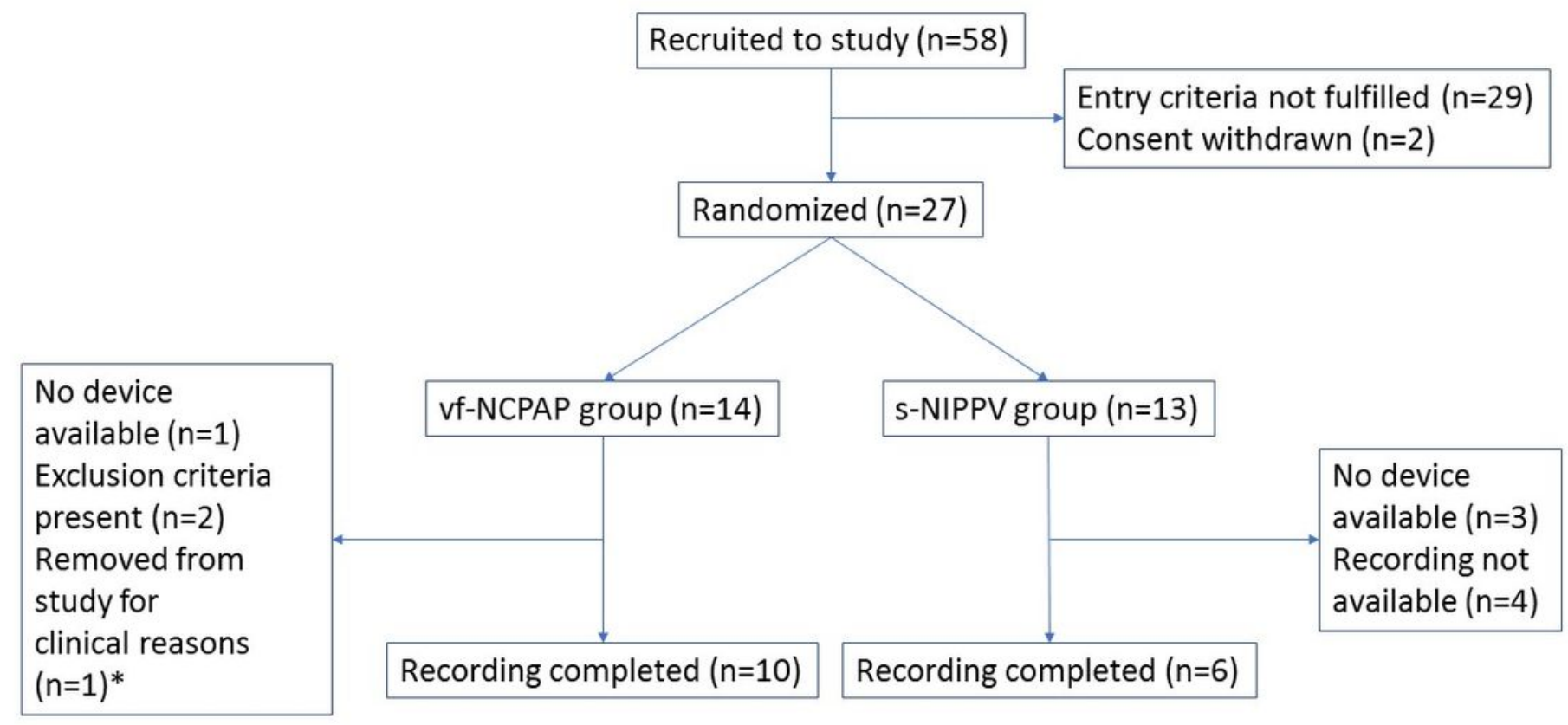


Figure 2

Patient flow, ${ }^{*}$ The attending physician decided that changing the ventilator was not advisable

\section{Supplementary Files}

This is a list of supplementary files associated with this preprint. Click to download.

- CPAPStudyCONSORTChecklistMGBMCPed.docx 